\title{
Eccentric compression behavior of long poplar columns externally reinforced by BFRP
}

Ling Zhou, Qing Liu*, Shengqiang Ma and Xia Han

\begin{abstract}
The column, which is the vertical main structural part of the building, bears the force transmitted from the upper beam and slab and is a crucial part of the structure. In this study, the columns with a rectangular section cut from poplar were reinforced by basalt fiber-reinforced polymer (BFRP) strips with four different reinforced configurations. The mechanical behaviors of the specimens were also investigated under different eccentricities. Experimental results are presented as follows: for the wooden columns under axial compression, the wooden column BFRP with one layer spaced apart, two layers spaced apart, one layer fully filled, and two layers fully reinforced demonstrated increased bearing capacities of $3.13 \%, 30.00 \%, 40.63 \%$, and $65.00 \%$, respectively; the longitudinal strain increased by $7.54 \%, 19.65 \%, 22.06 \%$, and $30.69 \%$, and the lateral strain decreased by $26.53 \%, 29.80 \%, 41.30 \%$, and $66.64 \%$, respectively. Meanwhile, for the wooden column subjected to eccentric compression, the bearing capacities of the aforementioned wooden column BFRP configurations increased by $8.70 \%, 19.56 \%, 23.91 \%$, and $30.43 \%$; the longitudinal strain of the wooden column increased by $25.41 \%, 35.20 \%, 39.52 \%$, and $41.85 \%$; and the transverse strain increased by $130.77 \%, 166.77 \%, 192.57 \%$, and $230.86 \%$. In addition, the finite element model was used to simulate the eccentric compression behavior of the specimen. However, the ultimate bearing capacity and deflection of the analyzed column were higher than the test value. This finding was due to the completely ideal state of poplar in Finite Element Analysis (FEA) modeling without the influence of some initial defects, such as knots. These values can roughly be used as a reference for experimental results for the repair and reinforcement of poplar structures in Xinjiang.
\end{abstract}

Keywords: Compressive behavior, Eccentricity, Poplar, Timber column, BFRP strips, FEA

\section{Introduction}

Wood is recognized as an important engineering material for livelihood and economic construction. In the civil engineering industry, traditional building materials, such as steel bars, cement, and clay bricks, not only consume a considerable amount of non-renewable natural resources and energy but also cause pollution to the natural environment. Compared with the traditional building materials, wood is a natural, environmentally friendly, and green material. Moreover, wooden structures are characterized by their light weight, good seismic performance, energy-saving potential, eco-friendliness, and comfort

\footnotetext{
*Correspondence: liuqing2666@163.com

Key Lab of Building Structure and Earthquake Resistance of Xinjiang,

School of Architectural and Civil Engineering of Xinjiang University,
}

Xinjiang 830000, China
[1]. Consequently, some developed countries and regions with abundant wood resources in the world attach considerable importance to the use of wood structures $[2,3]$. The vast majority of ancient existing buildings in China are wooden structures, such as the Forbidden City in Beijing and the Huiyuan Ancient City in Yili $[4,5]$. However, the structure of wood is complicated. Different tree species, parts of the same tree species, and similar tree species with different growth environments have varying mechanical properties [6]. Unlike metal and concrete, wood is a typical anisotropic material. Moreover, wood has natural defects, such as knots, corrosions, and cracks. These defects lead to a reduction in the bearing capacity and ductility of wooden structures. Some studies indicate that numerous ancient wooden structures worldwide have been damaged to varying degrees due to various reasons, such as cracks, worms, and decay; thus,
Springer Open
C The Author(s) 2021. This article is licensed under a Creative Commons Attribution 4.0 International License, which permits use, sharing, adaptation, distribution and reproduction in any medium or format, as long as you give appropriate credit to the original author(s) and the source, provide a link to the Creative Commons licence, and indicate if changes were made. The images or other third party material in this article are included in the article's Creative Commons licence, unless indicated otherwise in a credit line to the material. If material is not included in the article's Creative Commons licence and your intended use is not permitted by statutory regulation or exceeds the permitted use, you will need to obtain permission directly from the copyright holder. To view a copy of this licence, visit http://creativeco mmons.org/licenses/by/4.0/. 
reinforcing and restoring these precious historical heritages is necessary $[7,8]$.

Poplar (Populus tomentosa Carr.) is the most widely distributed environmental adaptation species worldwide. The largest poplar forest worldwide is located in the Tarim River Basin in Xinjiang, China, wherein the natural forest area covers more than 320,000 hectares, accounting for more than $90 \%$ of the country [9]. Compared with other types of trees, poplar is an important short-rotation tree from the family of Salicaceae. Poplar has the physical characteristics of rapid growth, saltalkali tolerance, cold resistance, and easy reproduction [10]. Therefore, as a structural material, poplar is crucial in the construction of villages and towns in Xinjiang. Apart from these advantages, poplar has some mechanical disadvantages, such as low elastic modulus and strength, loose fiber structure, and large creep. Although poplar has a large output in Xinjiang, all these wood defects impeded the comprehensive utilization of poplar and intensified the contradiction in use [11]. If poplar can be effectively reinforced, then this wood can be applied to traditional wooden structure buildings in Xinjiang villages and towns [12]. In the past, the renovation and reinforcement of wooden structures were mainly performed using conventional methods, including but not limited to the addition of restraint, tie rod, and pin methods as well as chemical and fiber bundle reinforcement methods. Traditional reinforcement methods not only increased the capacity in the static load of the structure but also demonstrated slight negligence, thereby possibly causing new damage to the structure and changing its original appearance $[7,12-15]$. The existing experimental and numerical studies revealed that fiber-reinforced polymer (FRP) composites, including carbon FRP (CFRP), glass FRP (GFRP), aramid FRP (AFRP), and basalt FRO (BFRP), are effective methods to enhance the strength and elastic modulus of wooden structures [16-18]. The FRP-reinforced method benefits from the superior properties of FRP, which is not only a rival in weight but also serves as a viable competitor considering the strength and corrosion resistance. A comparison of different types of fibers, such as CFRP, GFRP, and AFRP, revealed that the characteristics of BFRP have no distinct differences in strengthening structures. However, the price of basalt fiber is considerably lower than that of carbon and aramid fibers considering cost performance, and unique basalt resources are found in Xinjiang. Therefore, BFRP was used as the reinforcement material in the test.

The column, which is the vertical main structural part of the building, bears the force transmitted from the upper beam and slab. The column is subjected to axial and eccentric compressions based on the position of the force. Wooden columns are divided into long and short columns. A column is short when the ratio of length to width is less than or equal to 11 and long when this ratio is larger than 11 [19]. The long column is also called the Euler column. The main factor of the long column is material stiffness, which is unstable under compression, and its destruction is not caused by pure pressure. However, the long column will be damaged due to bends in the longitudinal direction, which generates torque. Therefore, scholars conducted numerous experimental investigations and related theoretical analyses on the compression performance of columns reinforced by FRP [20-29] mainly based on experimental research, and the raw materials on pine and cedar were tested. However, the experimental research and numerical simulation analysis of Xinjiang poplar are extraordinarily limited. For example, the literature [24-26] introduced an experimental study on CFRP wooden columns subjected to axial compression. The results showed increased capacity by approximately $0.2-8.3 \%$, and the hoop ultimate compressive strain could be recovered to $109.6-126.5 \%$ of unreinforced columns [27]. Shao Jinsong et al. [28] conducted a theoretical study on the axial compression performance of the FRP-reinforced wooden column. Their results indicated that the FRP horizontal reinforcement method could increase the bearing capacity and peak strain of the wooden column by $21.82 \%$ and $94.95 \%$, respectively. Ouyang $\mathrm{Yu}$ [29] conducted a stress performance test of GFRP-reinforced columns. The test showed that the axial load capacity of the column could be effectively improved when the GFRP reinforcement rate was within a certain range. However, the axial capacity no longer improved when the GFRP reinforcement rate was considerably large.

However, existing experimental and theoretical studies are mainly focused on the improvement of the axial compression performance of wooden columns strengthened by FRP, and studies on the FRP-reinforced wood column subjected to eccentric compression are relatively few [28, 30-33]. Eccentric compression is the main force mode for wooden columns in practical engineering. The possibility that the column is under true axial compression is considerably small. A certain eccentricity in the column with theoretical axial compression may be due to some factors, such as uneven material, off-axis load, and construction errors. Therefore, most columns in the structure are also eccentric compression members. Similarly, the columns on the edge of the building, especially the corner columns, are often subjected to the combined action of axial force and bending moment, thus producing an equivalent eccentric effect $[24,26,34-40]$. Hence, the Xinjiang poplar column was taken as the research object in this study. Experimental and analytical studies on columns subjected to eccentric compression were 
also conducted and investigated to understand the axial and eccentric compressive behaviors of BFRP-reinforced columns. The present study aims to observe the failure modes of the control and reinforced specimens, flexural behavior, ultimate strength, and the relationship of load and deflection. In addition, experimental and FEA analytical results were compared to verify whether the modeling could be used to analyze the eccentric compression behavior of the poplar column. Through relevant mechanical performance analysis, this finding will be a technical reference and theoretical basis for the repair and reinforcement of poplar columns in the ancient, village, and town buildings.

\section{Experimental program}

\section{Mechanical characteristics of materials}

\section{BFRP}

BFRP purchased from Xinjiang Tuoxin Basalt Fiber Products Co., Ltd. had a high tensile strength of $3200 \mathrm{MPa}$, an elastic modulus of $105 \mathrm{GPa}$, an elongation of $2.71 \%$, and a thickness of $0.132 \mathrm{~mm}$. The most commonly used adhesives for fiber composite materials in timbers are the oneand two-component epoxy resins. The two-component epoxy resins provided by the manufacturer (WCRCL) and mixed by weight with the ratio of 3:1 were used in this study. This resin had a high elastic modulus of $2885.1 \mathrm{MPa}$, a tensile strength of $53.9 \mathrm{MPa}$, axial compression strength of $101.7 \mathrm{MPa}$, and an elongation of $3.0 \%$. The properties

Table 1 Material mechanical properties

\begin{tabular}{lllll}
\hline Item & $\begin{array}{l}\text { Tensile } \\
\text { strength/ } \\
\text { MPa }\end{array}$ & $\begin{array}{l}\text { Modulus } \\
\text { of elasticity/ } \\
\text { GPa }\end{array}$ & $\begin{array}{l}\text { Axial } \\
\text { compression } \\
\text { strength/MPa }\end{array}$ & $\begin{array}{l}\text { Elongation } \\
\text { at break/\% }\end{array}$ \\
\hline BFRP & 3200 & 110 & - & 2.71 \\
Epoxy resin & 53.9 & 2.8851 & 101.7 & 3.0 \\
\hline
\end{tabular}

of the BFRP and reinforcement adhesive were tested and authorized by the Chinese Chemical Building Materials Testing Center. The main performance parameters of the material are shown in Table 1.

\section{Timber}

Measurement of moisture content A total of 27 samples were cut from poplar following the code of GB/T19312009 [41] and GB/T1928-2009 to test its moisture content [42]. The size of the sample was $20 \mathrm{~mm} \times 20 \mathrm{~mm} \times 20 \mathrm{~mm}$. First, the samples were numbered and weighed with an electronic scale before the test. Then, the moisture content of the wood was measured in a drying oven (model: 101-3A). The temperature in the oven during the test was controlled at $103 \pm 2{ }^{\circ} \mathrm{C}$, and the sample was continuously dried for eight hours. Samples were then taken out of the oven with tweezers and placed in a weighing bottle with desiccant, cooled to room temperature, and taken out for weighing. Last, the moisture content of the sample was calculated following Eq. 1 . The measurement process is shown in Fig. 1, and the test result of poplar average moisture content is $9.24 \%$ (Table 2).

$$
W=\frac{m_{1}-m_{0}}{m_{0}} \times 100 \%,
$$

where $W$ is the moisture content, $m_{0}$ is the moisture content before the test, and $m_{1}$ is the moisture content after drying.

\section{Table 2 Moisture content of poplar timber}

\begin{tabular}{llll}
\hline Specimen size & $\begin{array}{l}\text { Sample } \\
\text { quality } \\
\text { during test/g }\end{array}$ & $\begin{array}{l}\text { Dry sample } \\
\text { quality } / \mathbf{g}\end{array}$ & $\begin{array}{l}\text { Average } \\
\text { water } \\
\text { content } \\
\text { /\% }\end{array}$ \\
\hline $20 \mathrm{~mm} \times 20 \mathrm{~mm} \times 20 \mathrm{~mm}$ & 34.930 & 31.992 & 9.24 \\
\hline
\end{tabular}

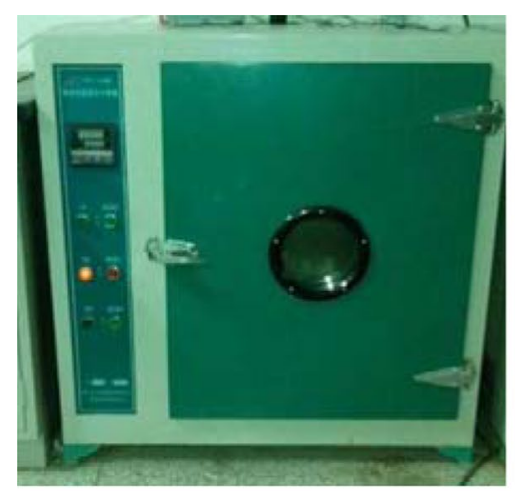

a Drying oven (Model: 101-3A)

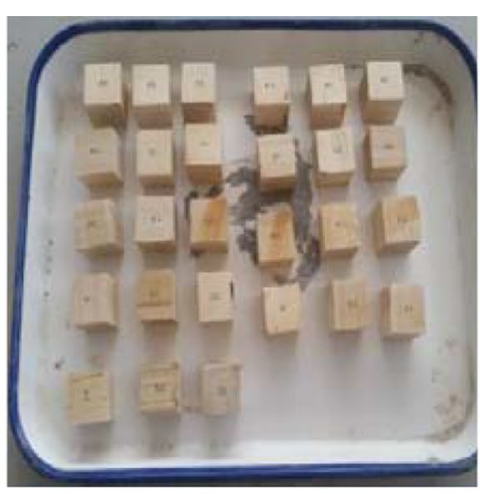

b Test block

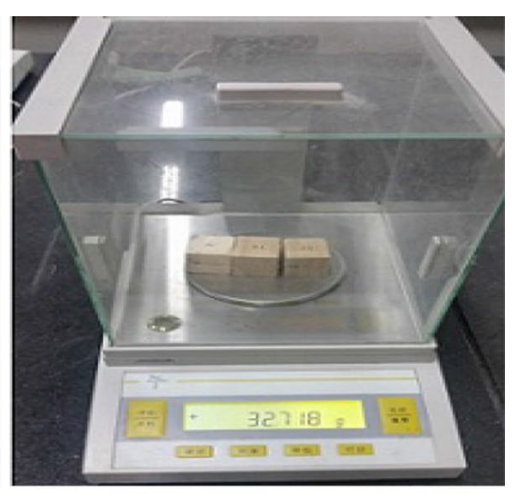

c Weighing test block

Fig.1 Sample drying and weighing process 
Mechanical characteristics of timber Sixty samples uniformly cut from the same poplar were divided into two groups to determine their tensile and compressive strengths along the grain and horizontal grains, respectively, following the code of GB/T1938-2009 [43]. Detailed information is shown in Fig. 2a. Notably, the tensile specimen was embedded between the upper and lower fixtures, and strain gauges were attached to the $15 \mathrm{~mm}$ width direction of the $4 \mathrm{~mm}$ thick specimen during the experiment. Continuous and uniform loadings were used to control the specimen to break within 1.5 and $2.0 \mathrm{~min}$, respectively. The tensile strength along the grain of the sample with moisture content was calculated following Eq. 2:

$$
\sigma_{w}=\frac{p_{\max }}{b t},
$$

where $p_{\max }$ is the failure load, and $b, t$ are the width and thickness of the sample, respectively. The basic mechanical properties of compression were tested in the following two parts: the compression along the grain and that against the transverse grain. The same kind of sample with a size of $30 \mathrm{~mm} \times 20 \mathrm{~mm} \times 20 \mathrm{~mm}$ was used to obtain the compressive strength in both tests as shown in Fig. 2b. The load and displacement values for each specimen were also collected during testing. The proportional limit load was then determined from the drawn loaddeformation diagram. Finally, the proportional limit stress of the wood in transverse grain compression was calculated following Eq. 3 [44]:

$$
\sigma_{y w}=\frac{p}{b l}
$$

where $\sigma_{y w}$ is the proportional limit stress of the wood in transverse grain compression, $p$ is the proportional ultimate load, and $b, l$ are the width and length of the specimen, respectively. Table 3 lists the three main properties of the poplar with $9.24 \%$ moisture content from testing.

\section{Details of test specimens and procedures}

The manufacturing process of this component is shown in Fig. 3. A total of 33 columns with rectangular cross sections were produced in this experiment to study the effect of different bonding methods and eccentricities on the mechanical properties of long columns from poplar. Table 4 shows 9 control columns and 24 reinforced with BFRP. In JBn-i-j-m/MBn-i-j-m, J is the column reinforced by BFRP strips with spacing; $M$ is fully reinforced by BFRP; $n$ is the number of layers

Table 3 Main mechanical characteristics of poplar

\begin{tabular}{lllll}
\hline Item & $\begin{array}{l}\text { Moisture } \\
\text { content (\%) }\end{array}$ & $\begin{array}{l}\text { Tensile } \\
\text { strength } \\
(\mathbf{M P a})\end{array}$ & $\begin{array}{l}\text { Compressive } \\
\text { strength } \\
(\mathbf{M P a})\end{array}$ & $\begin{array}{l}\text { Proportionality } \\
\text { limit stress } \\
(\mathbf{M P a})\end{array}$ \\
\hline$\sigma_{9.24}$ & 9.24 & 118.91 & 38.60 & 6.43
\end{tabular}
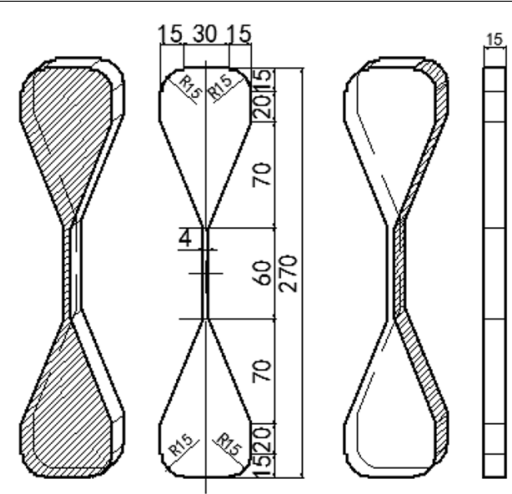

a

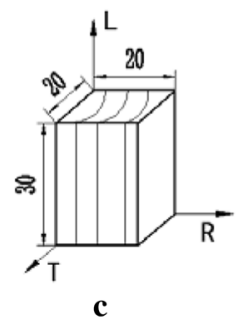

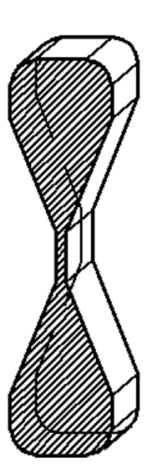
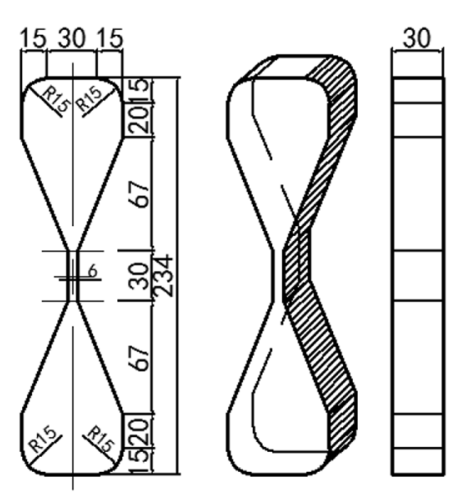

b

Fig.2 Details of tensile and compression testing sample: a tensile with rift grain, $\mathbf{b}$ tensile with radial, and $\mathbf{c}$ compression with rift grain (unit: $\mathrm{mm}$ ) 


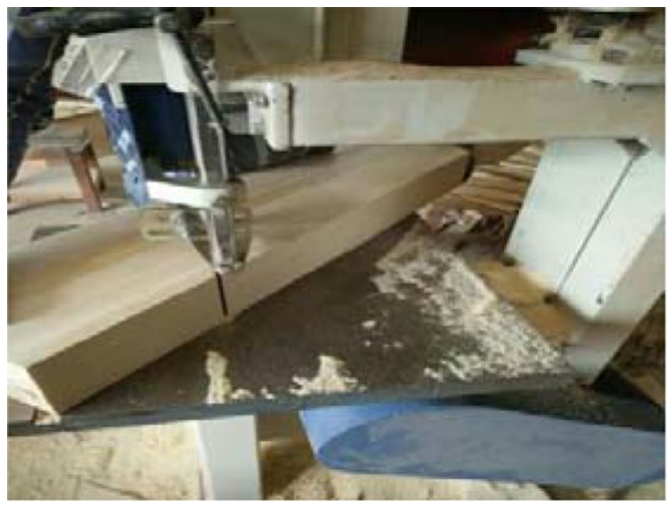

a

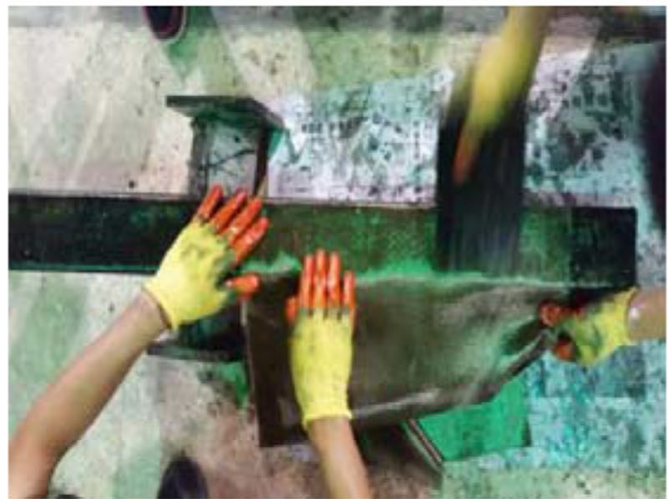

c

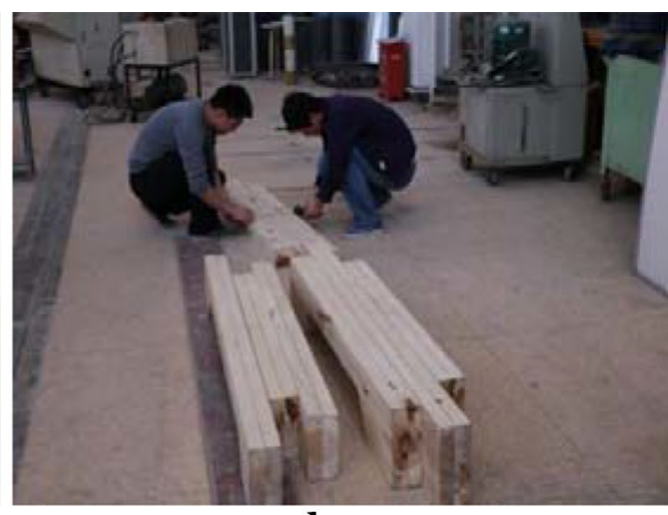

$\mathbf{b}$

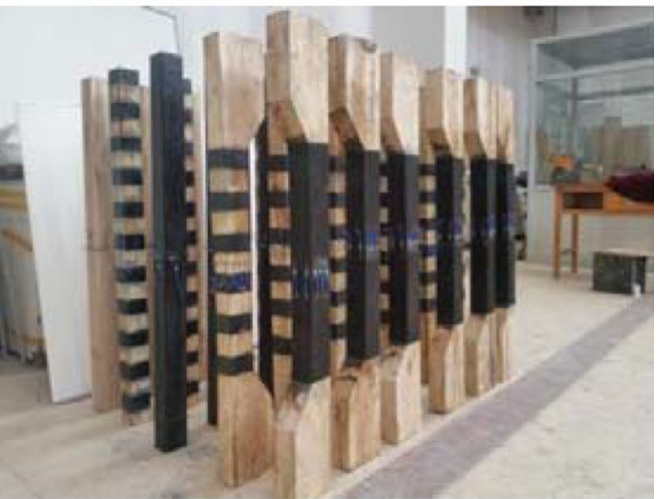

d

Fig.3 Main procedure of columns with strengthening BFRP: a processed wood, $\mathbf{b}$ underline, $\mathbf{c}$ primer and saturant painted, and $\mathbf{d}$ FRP bonded

Table 4 The basic parameters of the specimen

\begin{tabular}{|c|c|c|c|c|c|c|c|c|}
\hline \multirow[t]{2}{*}{ Specimen number } & \multirow[t]{2}{*}{ Reinforcement method } & \multicolumn{3}{|c|}{ Details Reinforced with BFRP } & \multirow{2}{*}{$\begin{array}{l}\text { Initial } \\
\text { eccentricity } \\
(\mathrm{mm})\end{array}$} & \multirow{2}{*}{$\begin{array}{l}\text { Specimen dimension } \\
(\mathrm{mm})\end{array}$} & \multirow[t]{2}{*}{$\rho_{\mathrm{BFRP}}(\%)$} & \multirow[t]{2}{*}{ Number } \\
\hline & & layers & Spacing (mm) & Width (mm) & & & & \\
\hline DBZ-0-1200 & Unreinforced & 0 & / & & 0 & $100 \times 100 \times 1200$ & 0 & 3 \\
\hline DBZ-50-1200 & & & & & 50 & & & 3 \\
\hline DBZ-100-1200 & & & & & 100 & & & 3 \\
\hline JB1-0-1200 & BFRP strips with spacing & 1 & 100 & 50 & 0 & $100 \times 200 \times 1200$ & 45.83 & 3 \\
\hline JB1-100-1200 & & & & & 100 & & & 3 \\
\hline JB2-0-1200 & & 2 & & & 0 & $100 \times 200 \times 1200$ & 91.66 & 3 \\
\hline$J B 2-100-1200$ & & & & & 100 & & & 3 \\
\hline MB1-0-1200 & Fully reinforced by BFRP & 1 & / & 1200 & 0 & $100 \times 200 \times 1200$ & 100 & 3 \\
\hline MB1-100-1200 & & & & & 100 & & & 3 \\
\hline MB2-0-1200 & & 2 & & & 0 & $100 \times 200 \times 1200$ & 200 & 3 \\
\hline MB2-100-1200 & & & & & 100 & & & 3 \\
\hline
\end{tabular}

considering BFRP; $i$ is eccentricity; $j$ is the length of column; $m$ is the number of the column. In addition, the distribution rate of BFRP is calculated following Eq. 4:

$$
\rho_{b f r p}=\frac{V_{b f r p}}{V_{y m z}}=\frac{n t_{b f r p} b_{b f r p} h_{b f r p}}{A H},
$$


where $V_{y m z}$ is the Poplar volume, $V_{b f r p}$ is the basalt fiber cloth volume, $n$ is the number of basalt fiber cloth pasting layers, $t_{b f r p}$ is the basalt fiber cloth thickness, $b_{b f r p}$ is the length of basalt fiber cloth, $h_{b f r p}$ is the width of the basalt fiber cloth. $A$ is the cross-sectional area of poplar, and $H$ is the Poplar height [45].

The standard code of the wooden structure testing method [46] indicates that the dimension of the column under axial compression was $100 \mathrm{~mm} \times 100 \mathrm{~mm} \times 1200 \mathrm{~mm}$. The size of the eccentrically compressed column was $100 \mathrm{~mm} \times 200 \mathrm{~mm} \times 1200 \mathrm{~mm}$. The longitudinal direction of the column was all along the grain direction. The tested columns were marked as DBZ, JB1, JB2, MB1, and MB2, where DBZ means unreinforced column, JBi is a BFRP space-reinforced column, $\mathrm{MBi}$ is a BFRP fully reinforced column, and $i$ is the number of adhesive layers. Details are shown in Fig. 4.

The following four procedures were performed to ensure the effective bonding of the interface between the BFRP cloth and column. First, the surface of the column was smoothed with a machine, and the sawdust and dust on the surface were cleaned by a blower. Second, the mixed epoxy resin was uniformly applied on the surface with the roller following GB 50,608-2010 [46]. Third, the BFRP cloth was pasted flatly on the column surface after curing the primer for $24 \mathrm{~h}$. Simultaneously, the air and the impregnated glue were squeezed out by the rigid plastic roller to prevent the generation of bubbles at the bonding interface. Finally, a thin layer of a saturating agent was applied to the fibers to facilitate full contact.

The test was conducted by a long column test machine with $5000 \mathrm{KN}$ capacity in the structural laboratory of Xinjiang University. According to the "Standard for Test Methods for Wooden Structures" (GB / T50329-2012) [47], the top and bottom of the column and the loading plate of the test machine were marked with cross lines to ensure the stability of the test component before the test. The static loading method was adopted in the specimen pressure test. Graded loading was adopted when the load was between 10 and $80 \%$ of the ultimate load, with each load level of $10 \mathrm{kN}$ and load holding time of $3 \mathrm{~min} ; 4 \mathrm{kN}$ was applied for each stage of the load in $80 \%$ of the ultimate load, and the load holding time was $3 \mathrm{~min}$. When

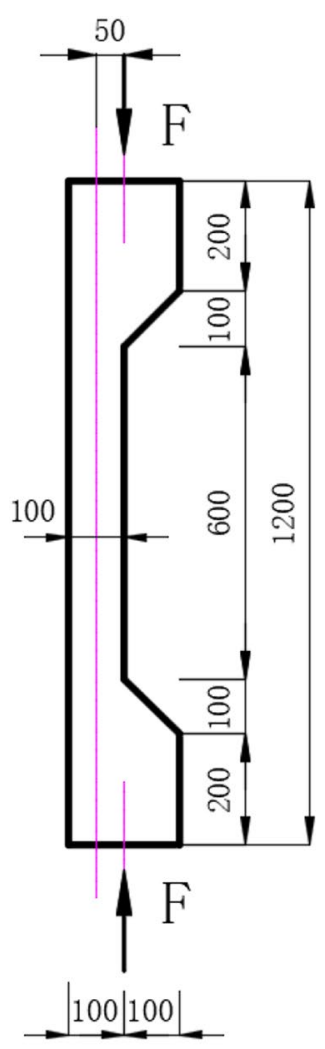

a
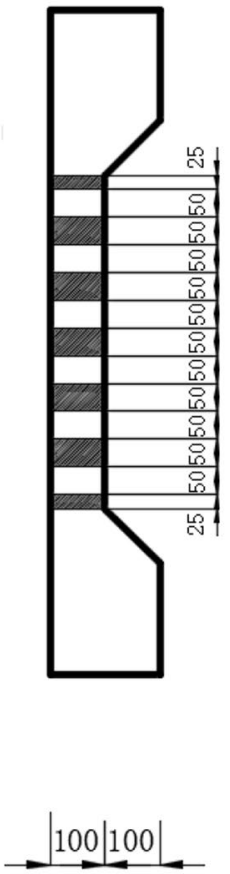

b

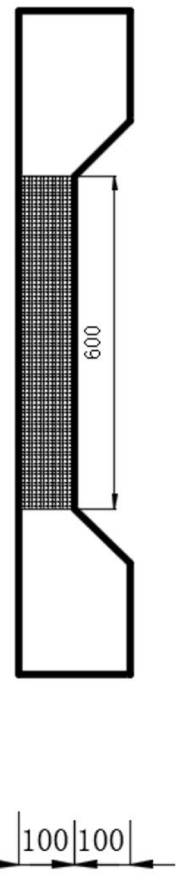

c

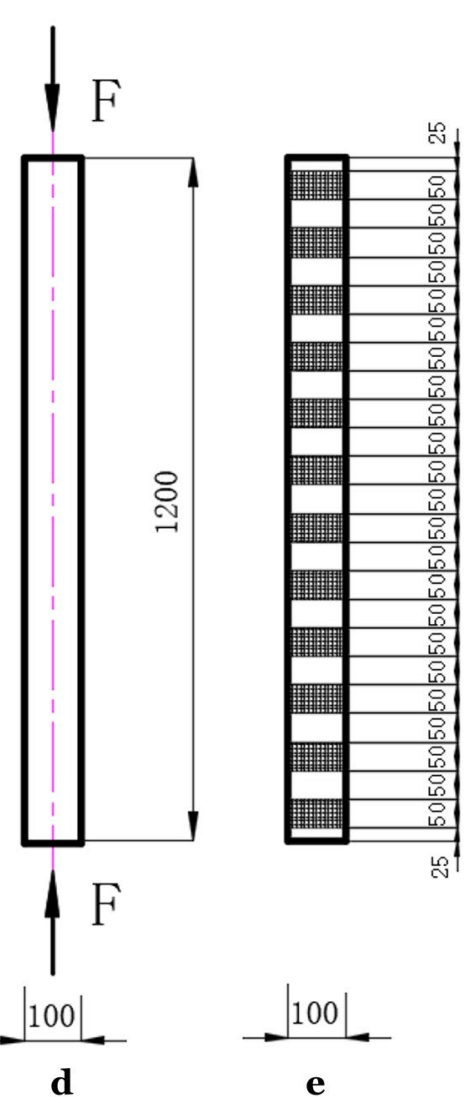

d $\mathbf{e}$

Fig.4 Specimen size and BFRP bonding method: eccentric columns: a DBZ, b JB1 and JB2, c MB1 and MB2, axial compression columns: $\mathbf{d}$ DBZ, and e JB1 and JB2 unit: $\mathrm{mm}$ 
the load limit was reached, the loading method with displacement control was adopted in the test. The running speed of the indenter of the testing machine was controlled at $1.00 \mathrm{~mm} / \mathrm{s}$.

Four displacement gauges were arranged in the middle of the column and two were arranged on the top to determine the displacement of the column for eccentric. In addition, the members of eccentric compression were vertically attached with strain gauges on the tension side, the compression side, and the middle of the side surface to measure the specimen strain. A protective fixture was provided at the loading end to prevent splitting damage at the loading end of the column.

\section{Experimental results and discussions Results of tested specimens}

1) Summary of testing results of DBZ under different eccentricities.

\section{Failure modes of DBZ}

Figure 5 shows the failure mode of the unreinforced columns under different eccentricities. DBZ-0-1200 was damaged due to compression, while DBZ-50-1200 and DBZ-100-1200 were both bent and damaged due to the broken tensile side wood fiber. However, their damage positions were different. In the early stage of loading, no changes were observed in all specimen groups for the DBZ-0-1200, DBZ-50-1200, and DBZ-100-1200. As the load increased, the compression side was wrinkled, the
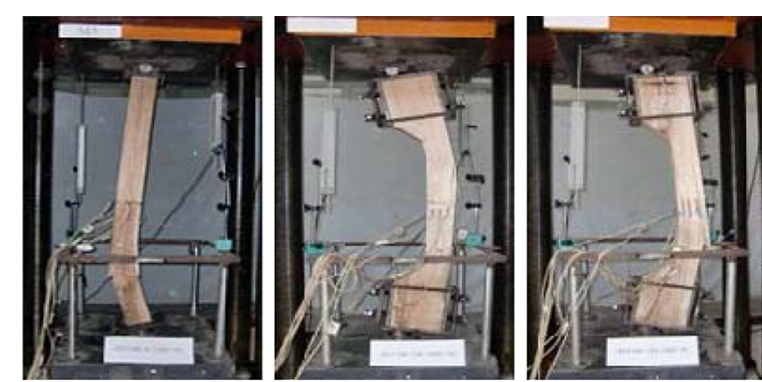

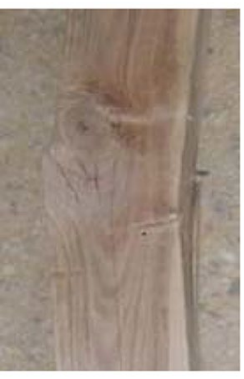

$\mathbf{a}$

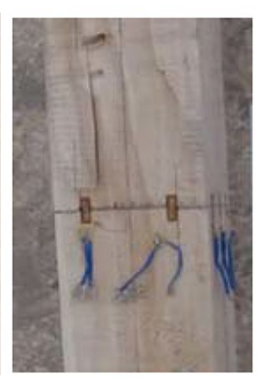

b

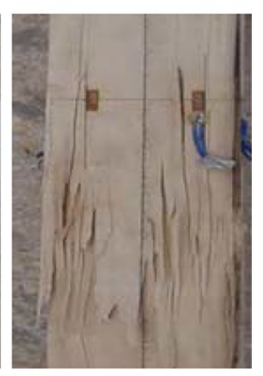

c
Fig.5 The failure form of DBZ with different initial eccentricities with a $0 \mathrm{~mm}, \mathbf{b} 50 \mathrm{~mm}$, and c $100 \mathrm{~mm}$ fracture sound was produced from wood fiber, and then the crack extended slowly upward. When the eccentricity is large, the tearing sound from the wood was early, the crack rapidly extended from the middle of the columns, and the lateral flexural displacement rapidly increased with the tearing sound from the tensile fiber. When the ultimate bearing capacity was reached, the damaged position of the wooden columns was 260,50 , and $150 \mathrm{~mm}$ below, above, and in the middle, respectively. The results showed that an increase in the initial eccentricity would lead to a decrease in the bearing capacity considering the positive section of the eccentric column, and the peak deflection corresponding to the peak load would gradually increase. A large eccentricity resulted in the overall bending of the specimen during the loading process. The wood fibers on the compression side were eventually crushed, and the poplar column was destroyed.

\section{Load-strain response}

As previously mentioned, 10 strain gauges were bonded to four sides of the tested columns along the middle of the column. The collected results implied that a large eccentricity leads to a large strain and a small ultimate bearing capacity. Figure 6 shows the load-strain diagram of DBZ under different eccentricities. DBZ-0-1200, DBZ-50-1200, and DBZ-100-1200 demonstrated the fastest growth of the compression strain on the compression side, while that on the tension side was relatively slow. This finding was due to the simultaneous existence and cancelation of tensile and compressive strains. The columns entered the plastic stage in the later stage of

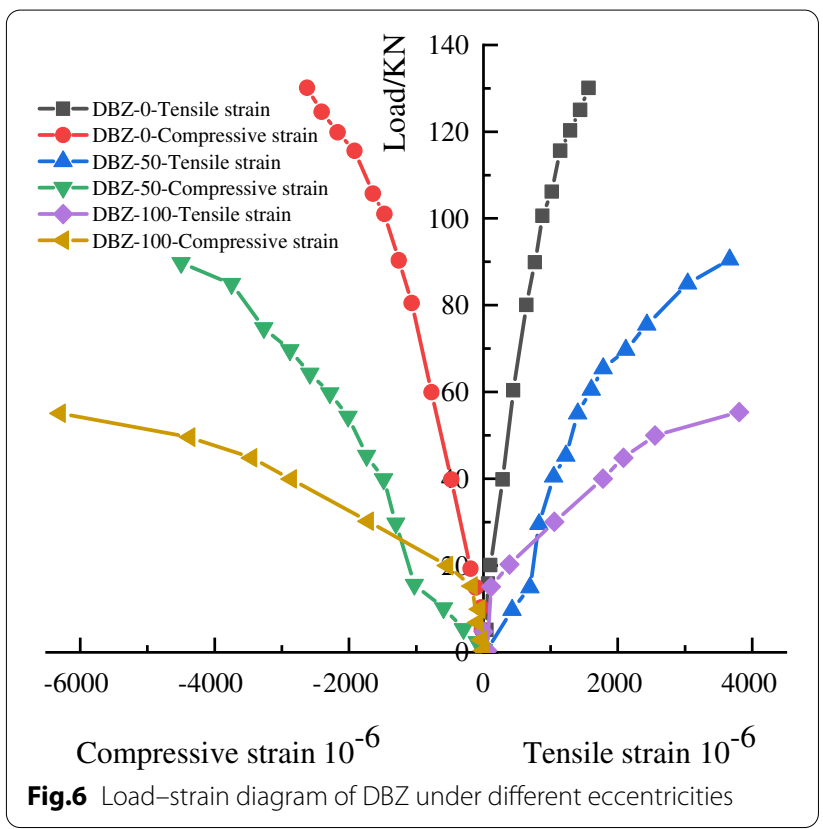


loading, and the strain growth accelerated. The fiber on the compression side of the column first reached the ultimate compressive strain, and the wood fiber on the compression side of the column demonstrated buckling and wrinkling. Interestingly, the load growth rate during this time slowed down, and the yield surface gradually moved toward the tension side. Afterward, the column with a large eccentricity would fail earlier than that with a small eccentricity due to the rapid increase in the additional bending moment of columns with large initial eccentricity. Comparing the strain distributions of the DBZ-01200, DBZ-50-1200, and DBZ-100-1200 at the ultimate stage, the tensile and compressive strains of DBZ-1001200 were larger than those of DBZ-0-1200 and DBZ50-1200. This condition could be attributed to the large column deformation and the fast strain growth due to large eccentricity. Thus, eccentricity decreased the unreinforced timber column for their capacity.

\section{Load-deflection response}

Figure 7 shows that the load-displacement curves of the specimens with an initial eccentricity of 0,50 , and $100 \mathrm{~mm}$ have the same trend. The mid-span (horizontal) and top column displacements, respectively, increased non-linearly and linearly when the load ranged from $0 \mathrm{KN}$ to $20.00 \mathrm{KN}$. This finding indicates that all the specimens were in the elastic stage. As the loading increased until the ultimate load, its midspan and top (longitudinal) displacements increased substantially non-linearly. Thus, the specimen was in the elastoplastic stage. The overall trend of the loaddeflection curves revealed that in the same loading

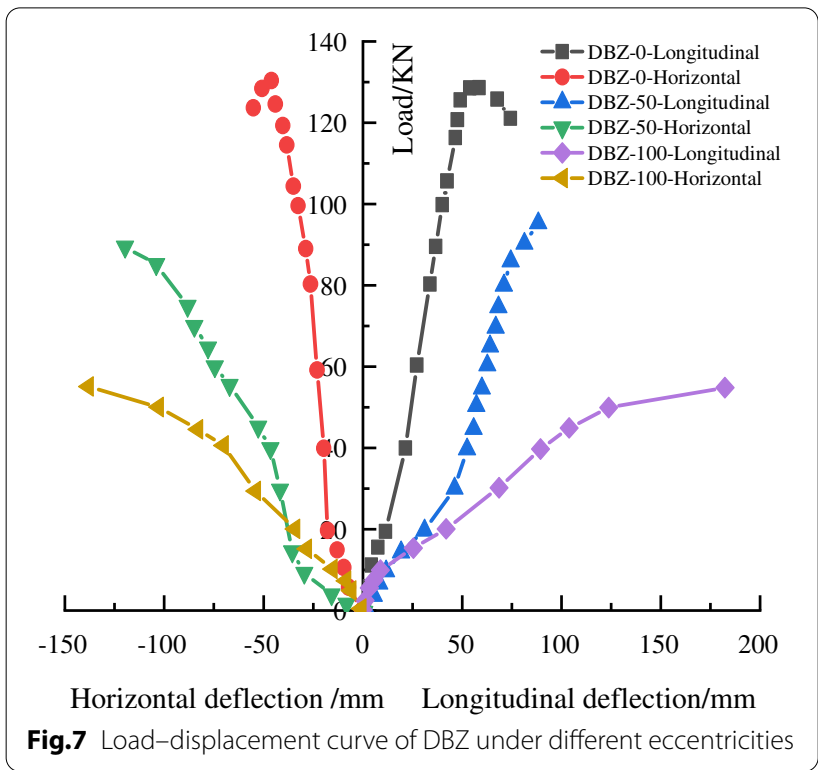

values, such as $40 \mathrm{kN}$, the mid-span deflections of the columns with different eccentricities, namely DBZ-01200, DBZ-50-1200, and DBZ-100-1200, were 19.64, 46.51, and $70.29 \mathrm{~mm}$, respectively. Therefore, the mid-span deflection was accordingly magnified with increased eccentricity at the same loading state. Based on the comparison of DBZ-0-1200, DBZ-50-1200, and DBZ-100-1200, Fig. 7 shows that the bending moment acting on the end of the specimen increases with the initial eccentricity, the bearing capacity of the specimen decreases, and the mid-span and top displacements increase with the initial eccentricity. Specifically, the increase in the mid-span displacement of the specimen was larger than that in the top displacement. Wood, as an anisotropic material, has a modulus of elasticity along grains larger than that of transverse grains, and its mechanical properties are considerably affected by factors, such as knots and humidity. The specimen is prone to mid-span deflection under vertical load. Thus, some of the data in the test results inevitably have a certain degree of dispersion.

2) Summary of testing results of reinforced column under different eccentricities.

\section{Failure modes of tested specimens}

A total of 12 reinforced columns with an eccentricity of 100 were investigated during the testing procedures using the pasting method. The experimental investigation revealed that the two failure modes of reinforced columns were broken in the shear plane and bending failure (Table 5). This result demonstrated that the stiffness and ductility of the columns were effectively enhanced by BFRP. Interestingly, the pasting method and the number of layers had a certain effect on deformation under the same load. The following descriptions of the specimen behaviors will be summarized by the overall condition of columns in each batch.

Figure 8 shows that the failure location of JB1-1001200 occurred in the unreinforced section, the bending failure was caused by the development of the wood fiber compression, and the failure was accompanied by a "pop" sound. The failure of JB2-100-1200 was caused by the longitudinal wood fiber of approximately $100 \mathrm{~mm}$ in the middle of the tension side being pulled off, and the failure had a certain abruptness. MB1-100-1200 was broken due to the extrusion of the tensioned surface. Simultaneously, the longitudinal BFRP on the tensile side of the specimen partially slipped. The longitudinal flexural deformation of MB2-100-1200 slowly developed during the compression process, and BFRP was cut due to the shear failure of the wood fibers in the compressed section (Table 5). This finding indicates that the reinforcement method with full sticking is better than that with interval sticking. 
Table 5 Failure mode of the tested specimens

\begin{tabular}{|c|c|c|c|c|c|c|}
\hline \multirow[t]{2}{*}{ Specimen number } & \multirow[t]{2}{*}{ Reinforcement method } & \multicolumn{3}{|c|}{ Details reinforced with BFRP } & \multirow{2}{*}{$\begin{array}{l}\text { Initial } \\
\text { eccentricity } \\
(\mathrm{mm})\end{array}$} & \multirow{2}{*}{$\begin{array}{l}\text { Failure mode } \\
\text { of the tested } \\
\text { specimens }\end{array}$} \\
\hline & & layers & Spacing (mm) & Width (mm) & & \\
\hline JB1-0-1200 & BFRP strips with spacing & 1 & 100 & 50 & 0 & Bending failure \\
\hline$J B 1-100-1200$ & & & & & 100 & Bending failure \\
\hline JB2-0-1200 & & 2 & & & 0 & Bending failure \\
\hline JB2-100-1200 & & & & & 100 & Bending failure \\
\hline MB1-0-1200 & fully reinforced by BFRP & 1 & / & 1200 & 0 & Shear failure \\
\hline MB1-100-1200 & & & & & 100 & Bending failure \\
\hline MB2-0-1200 & & 2 & & & 0 & Shear failure \\
\hline MB2-100-1200 & & & & & 100 & Shear failure \\
\hline
\end{tabular}

\section{Load-deflection and load-strain responses}

Figure 9 reveals the load-deflection and load-strain relationships considering reinforced columns with BFRP sheets. The overall trend of load-deflection curves shows the following results: considering longitudinal displacement and strain, the longitudinal displacement of the specimen within $0-40 \mathrm{KN}$ was in the elastic stage, and the curve changed approximately linearly. As the loading increased until the ultimate load, the longitudinal displacement suddenly increased, and the column failed due to rupture. Compared with the unreinforced column, the longitudinal deformation of the BFRP-reinforced column increased by $12.61 \%$, $18.54 \%, 27.17 \%$, and $40.51 \%$; the increase in the longitudinal strain of reinforced wooden columns was $25.41 \%$, $35.20 \%, 39.52 \%$, and $41.85 \%$, respectively. BFRP is a unidirectional tensile material. Thus, pasting BFRP in the longitudinal direction of the column cannot effectively restrain the lateral deformation of the wood fiber in the compression zone. The cross-sectional area of the compression zone expands with the increase in fiber distribution rate. Therefore, the ultimate failure is due to the cracked wood fibers in the compression zone. Considering lateral deflection and strain, compared with the unreinforced column, the increase in the lateral displacement of the reinforced column was $214.76 \%, 243.15 \%, 260.98 \%$, and $264.58 \%$; the increase in lateral strain was $130.77 \%, 166.77 \%, 192.57 \%$, and $230.86 \%$, respectively. Notably, longitudinal pasting was more effective in suppressing the longitudinal bending deformation of the wooden columns than horizontally pasted BFRP. The fiber strips demonstrated circumferential hoop effects on the lateral displacement for wood columns. Therefore, the columns had the highest bearing capacity and deflection at the mid-span because the BFRP strip emphasized the applied strain in improving the stiffness of the reinforced column.

\section{Finite element analysis (FEA) simulation}

The finite element model of composite materials with simply supported ends was established using the general FEA software from ANSYS [48] to further understand the compressive properties of BFRP-reinforced wooden columns, and the results were compared with the test results. The next section summarized the detailed modeling approach.

\section{Basic assumption of a finite element model of poplar column}

Wood is a complex anisotropic material [49]. Thus, the following assumptions are made when establishing a finite element model of BFRP-reinforced wooden columns. (1) In the elastic phase, the elastic modulus of the material at the interface is equal to that of the material under tension when the wood is tensioned. (2) BRFP is only under tension when the stress-strain relationship indicates linear elasticity. (3) The cross section of the poplar column remains flat after the wood is loaded, and subsequent calculation of the bearing capacity can be analyzed following the plane cross-section assumption. Therefore, the BFRP will produce a hysteresis strain when the poplar wood is reinforced. The result is the actual strain of BFRP as long as the calculated BFRP is subtracted from the hysteresis strain. (4) The BFRP sheets and the wood at the same position only cause $\mathrm{y}$-direction slip, the $\mathrm{x}$ and $\mathrm{z}$ directions are well bonded, and the strain is coordinated.

\section{Model characterization}

Wood is a typical orthotropic material. Thus, the SOLID45 element suitable for anisotropic materials in ANSYS is used for the wood column as shown in Fig. 10. The element is defined by eight nodes and anisotropic material parameters. The direction of the anisotropic material corresponds to the element coordinate system direction. Each node has three degrees of freedom for translation in the xyz directions to match the orthotropic properties of the wood material. 

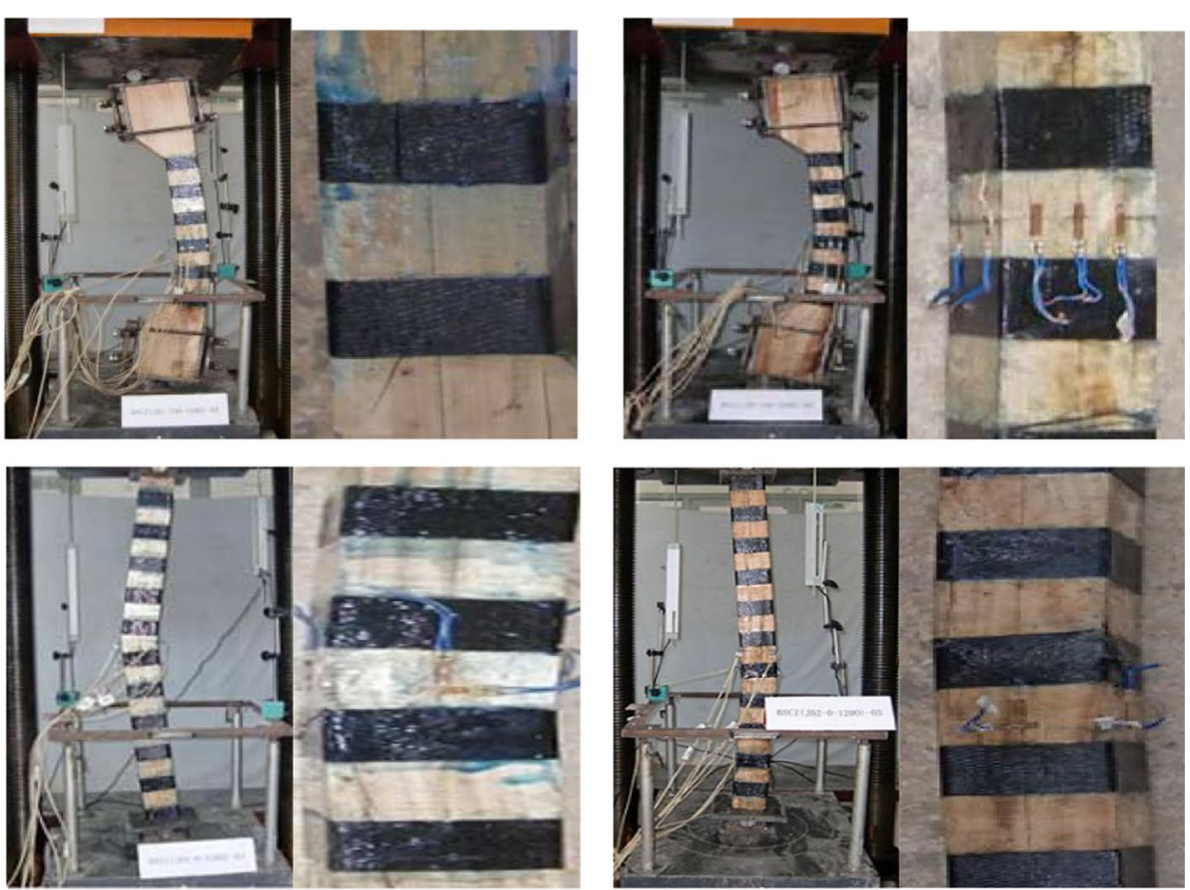

JB2 b
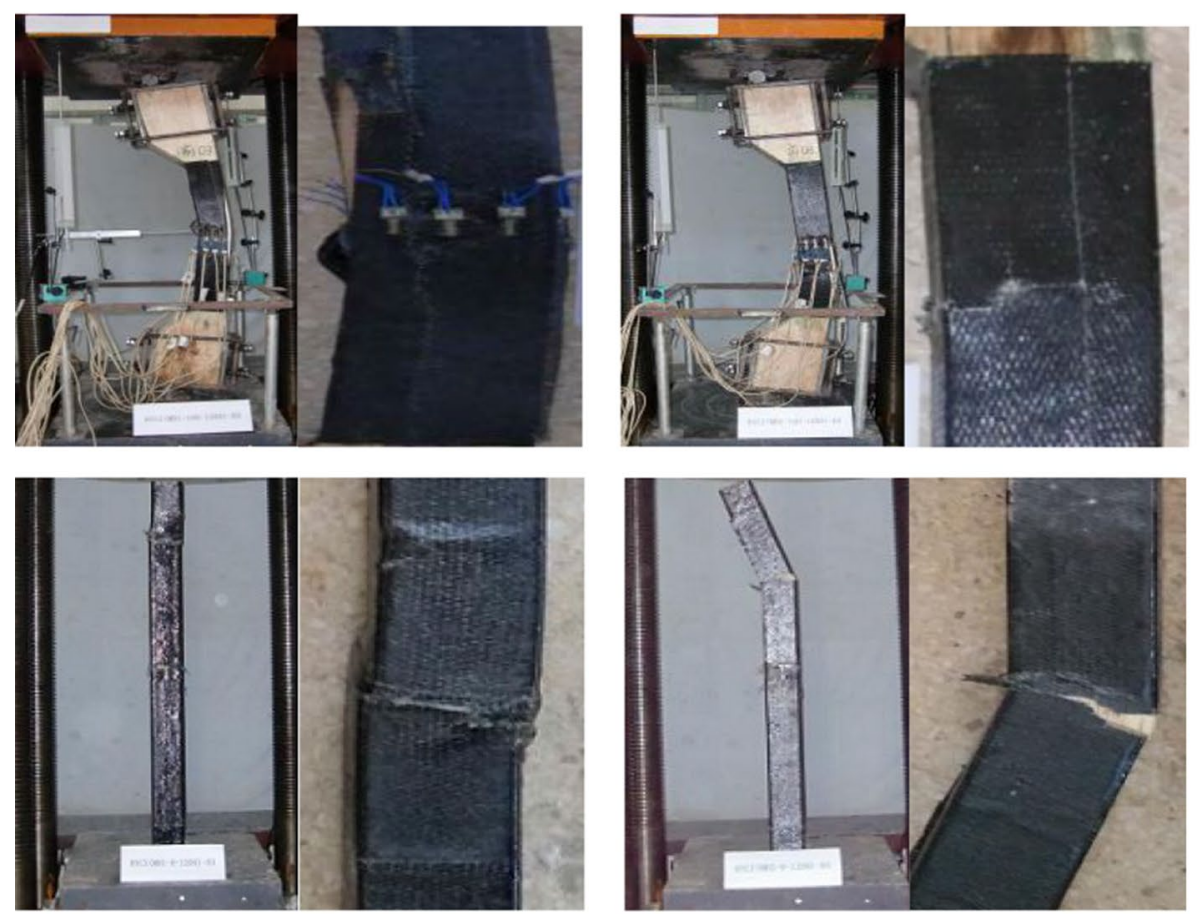

MB1 c

MB2 d

Fig. 8 Failure mode of reinforced column with an eccentricity of $0 \mathrm{~mm}$ and $100 \mathrm{~mm}$ under compression

The BFRP, which has the characteristics of isotropic and elastic materials, can be modeled with the SHELL63 element with large deformation and stress stiffening. Each node of the element has six degrees of freedom: the degrees of freedom of translation and rotation along the $\mathrm{X}, \mathrm{Y}$, and $\mathrm{Z}$ directions of the nodal 


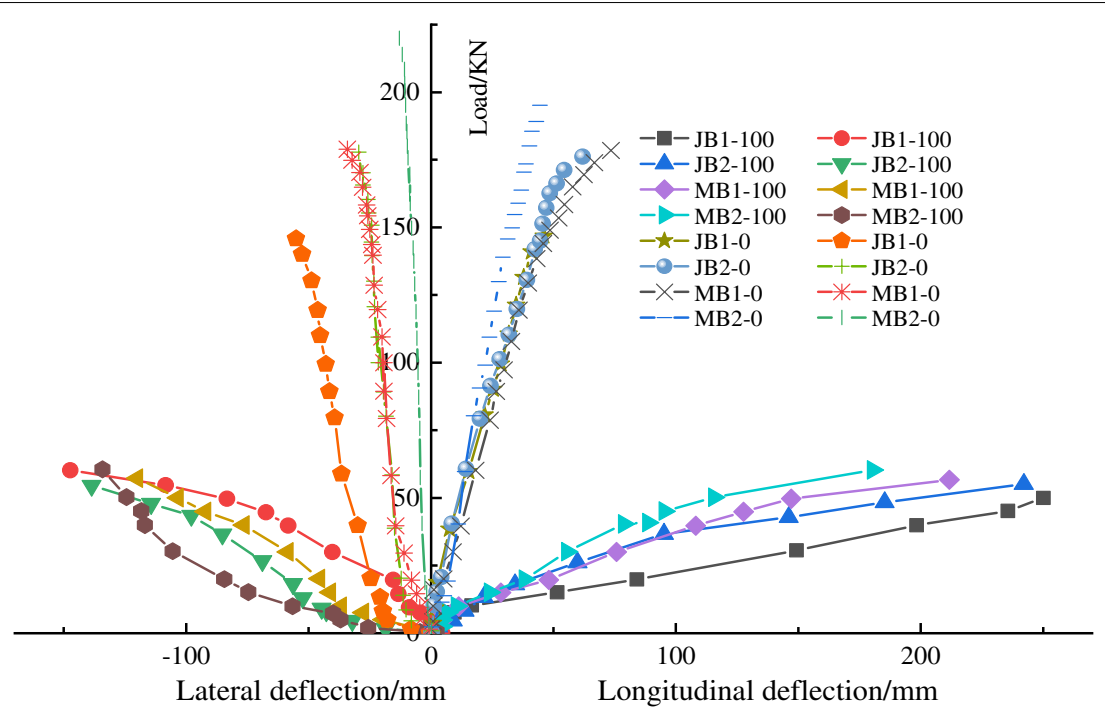

a

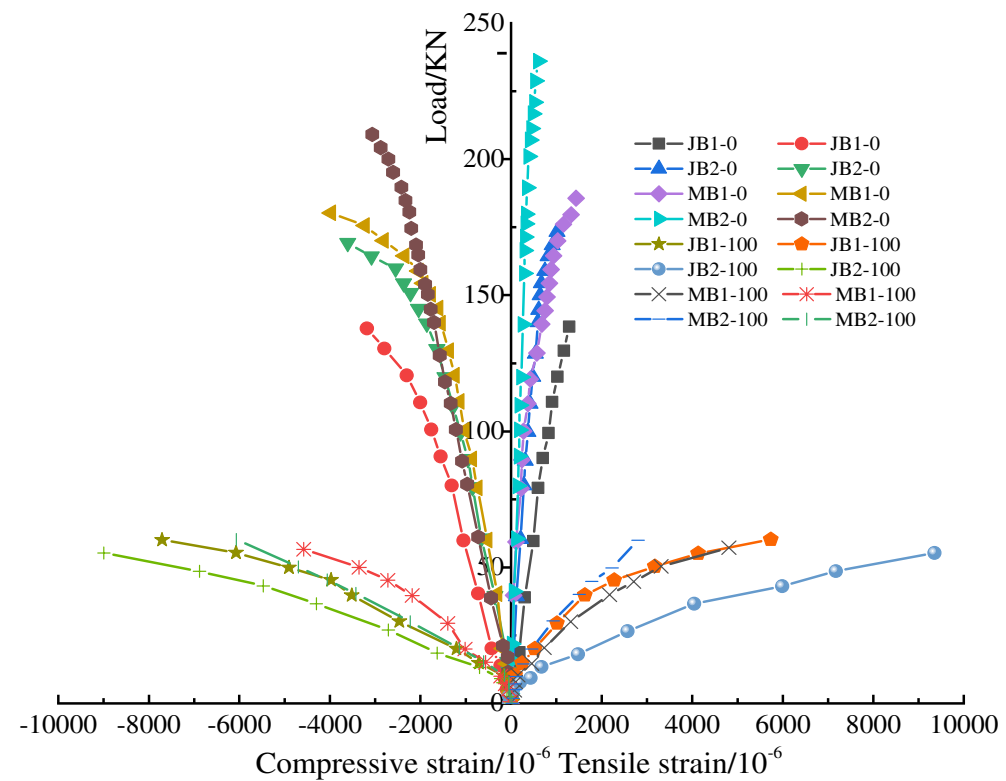

b

Fig. 9 Load — strain curve (a) and load-displacement curve (b) of reinforced column with an eccentricity of $100 \mathrm{~mm}$ under compression

coordinate system. The geometry, position, and coordinate system of Shell63 are shown in Fig. 11.

Two methods are available to deal with the interface problem in finite element simulation. The first method is to couple the node with the wood directly, thus ignoring the role of the interface. The second method is to set the interface element COMBIN39 between FRP and wood. This paper uses the latter. COMBIN39 is employed to simulate the adhesive layer between the BFRP and the column. COMBIN39 is referred to as a non-linear spring element, which is a unidirectional element with a nonlinear generalized force-deformation curve (referred to as the F-D curve, Fig. 12). Axial spring is the uniaxial tension and compression; each node has three translational degrees of freedom and no bending or torsion. In the finite element simulation, three spring elements are 


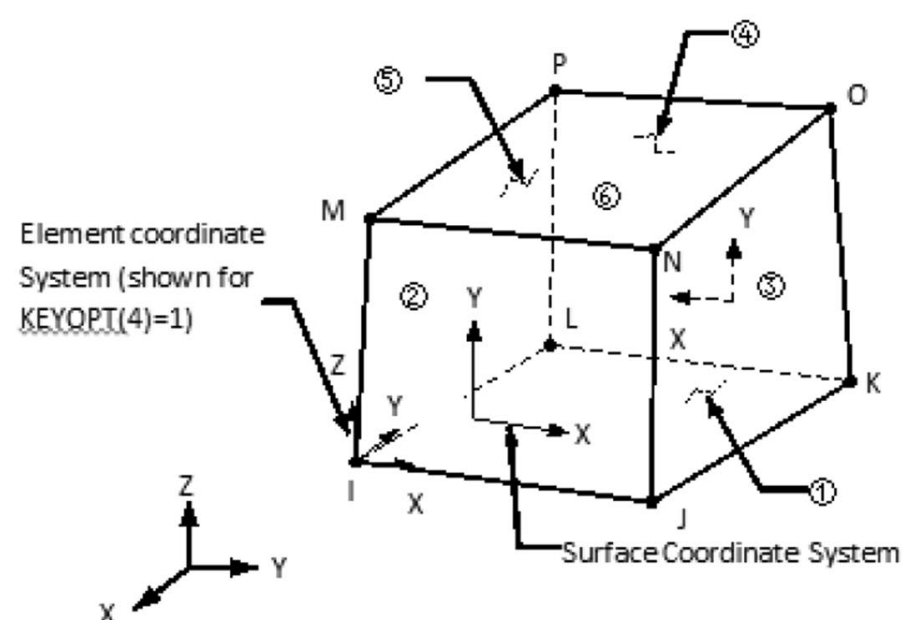

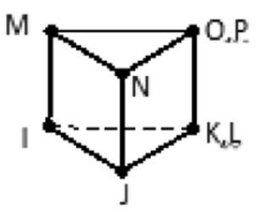

Prism Option

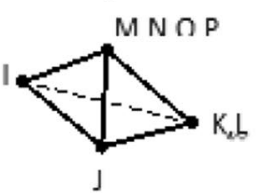

Tetrahedral Option-

not recommended

Fig. 10 Details of finite elements: SOLID45 [50]

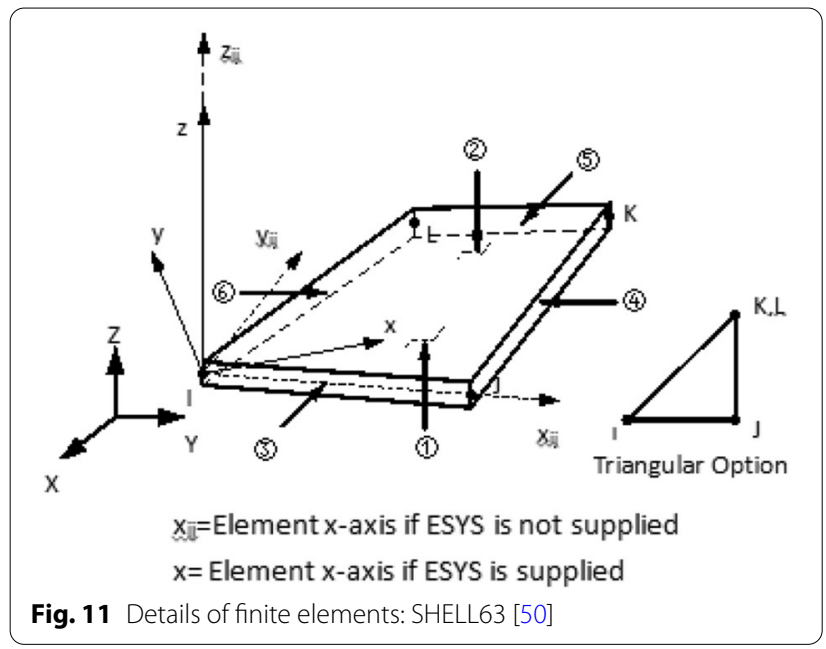

often set in a pair of nodes corresponding to the wooden column and BFRP to simulate the normal, longitudinal, and transverse tangential slips of the bonding interface [51] (details are shown in Fig. 13).

In this analysis, BFRP-reinforced columns are mainly considered to generate slippage in the y direction (longitudinal). Therefore, COMBIN39 is set in the corresponding nodes in the y direction between the wooden column and the BRFP to simulate the longitudinal slip occurrence. In particular, the length of the spring element is equal to the thickness of the bond layer $[57,58]$.

The geometric model was meshed with a length of $25 \mathrm{~mm}$. The solution was converged when the displacement increment of the two adjacent load steps was less than two norm precisions.

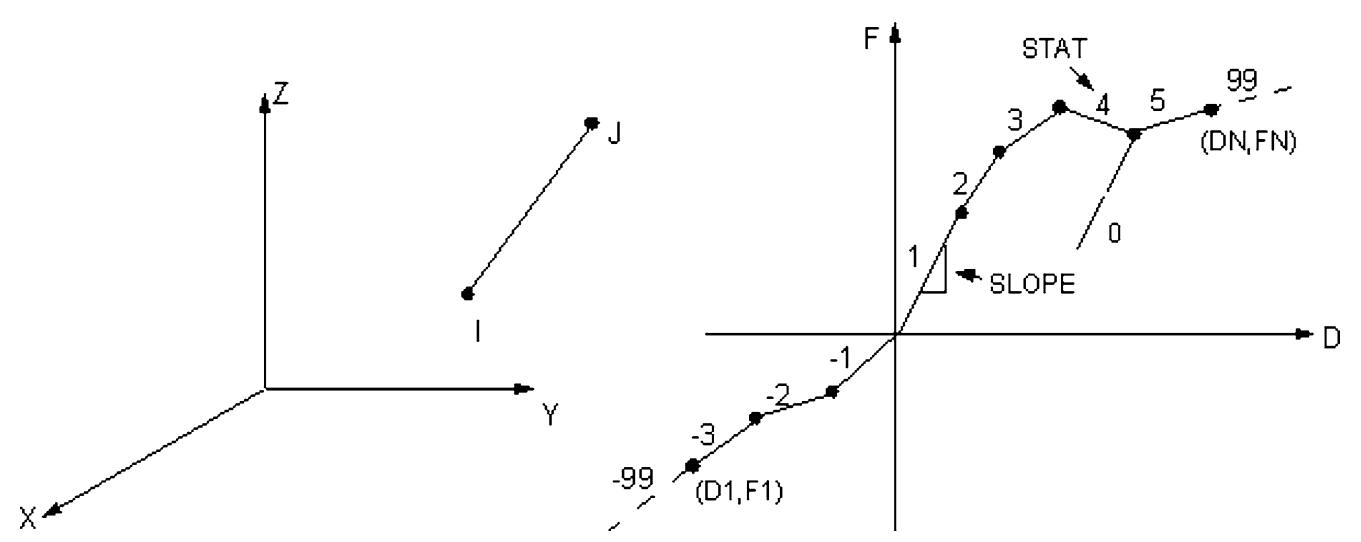

Fig.12 F-D curves of COMBIN39 [50] 


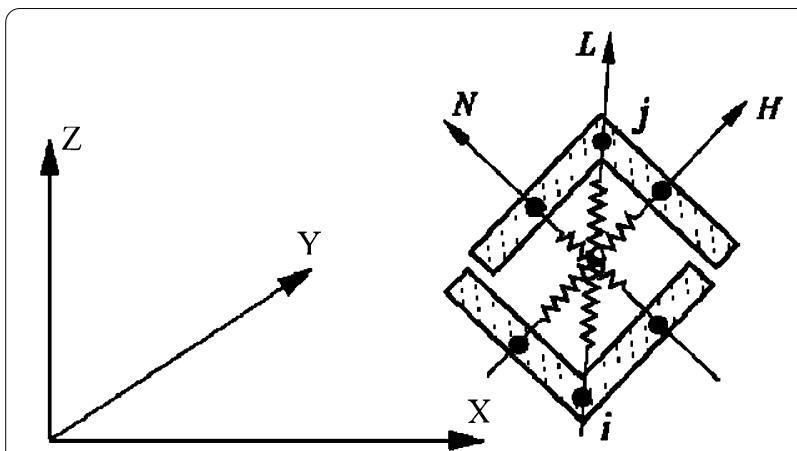

Fig.13 Direction setting diagram of Spring elements COMBIN39 of the adhesive [52]

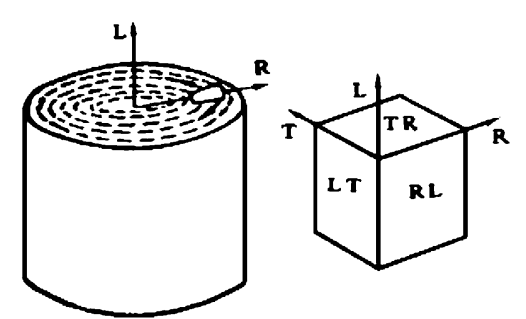

Fig. 14 Schematic diagram of wood orthogonal symmetry

\section{Uniaxial stress-strain model of poplar}

Considering the orthotropic nature of wood, the $\mathrm{L}$ direction is set to longitudinal, the $\mathrm{R}$ direction is set to radial, and the $\mathrm{T}$ direction is set to tangential (Fig. 14). The elastic characteristics of wood are usually expressed by elastic constants, including elastic modulus $E_{\mathrm{i}}$, Poisson's ratio $\mu_{\mathrm{ij}}$, and shear modulus $G_{\mathrm{ij}}$.

Therefore, the constitutive relation of poplar in the elastic stage can be expressed by using the tensor method, that is, $\sigma_{i j}=c_{i j k l} \varepsilon_{k l}(i, j, k, l=1,2,3)$, and the elastic parameters are shown in Table 6 . The parameter $c_{i j k l}$ is the coefficient of elasticity. The generalized Hill yield criterion, which is a further extension of the Hill yield criterion, was used in the plastic stage due to the following reasons [53-55]: This criterion not only considers the difference in yield strength in the three orthogonal directions of the material but also the different yield strengths in the tensile and compressed states. This characteristic is similar to the properties of wood. Thus, the generalized HILL yield criterion is used as the strength criterion in the plastic stage. The plastic parameters are shown in Table 7.

Figure 15 shows the FEA model of the FRP-reinforced column. The column, which is hinged at both ends, was $100 \mathrm{~mm} \times 100 \mathrm{~mm} \times 1200 \mathrm{~mm}$ and simulated under eccentric compression. Thin steel flat plates $(100 \mathrm{~mm} \times 100 \mathrm{~mm} \times 20 \mathrm{~mm})$ attached with a column at each end were considered, thereby preventing local timber crushing. SOLID65, SHELL41, and COMBIN39 spring units were, respectively, used for the wood column, BFRP, and bonding layer to analyze the mechanical characteristics of the wrapped column with BFRP. The geometric model was meshed with a length of $25 \mathrm{~mm}$. The solution was converged when the displacement increment of two adjacent load steps was less than two norm precisions.

\section{Results of FEA simulation}

Figure 16 shows a comparison of the load-displacement for the FEA and test results of JG1-100-1200, JG2-100-1200, MB1-100-1200, and MB2-100-1200. Among the curves, the finite element results are 52, 57, 56 , and $62 \mathrm{kN}$, and the test results are 50,55, 57, and 60 $\mathrm{kN}$. This figure reveals that the error between the FEA and the test bearing capacity is approximately $8 \%$, and the numerical simulation results agree well with the test curve results. Notably, the curve trend of JG1-1001200 and JG2-100-1200 shown in Fig. 16 can be divided into the following two stages: the load $0-27 \mathrm{kN}$ is in the elastic stage, and the displacement linearly increases with the load. The JG1-100-1200 and JG2-100-1200 enter the plastic stage when the load reaches $27 \mathrm{kN}$. In addition, each curve has an inflection point, the slope of the curves instantaneously decreases, and the displacement rapidly increases until their load limit. Thus, the

Table 7 Plastic constitutive parameters of poplar

\begin{tabular}{llll}
\hline Direction & R & L & T \\
\hline Tensile yield stress (MPa) & 4.62 & 32.956 & 4.4 \\
Tangent modulus under tension (MPa) & 0 & 3800 & 0 \\
Compressive yield stress (MPa) & 4.631 & 16.324 & 5.079 \\
Tangent modulus of compression (MPa) & 0 & 3800 & 0 \\
Shear yield stress (MPa) & 5 & 5 & 5 \\
Tangent modulus under shear (MPa) & 0 & 0 & 0 \\
\hline
\end{tabular}

Table 6 Elastic constitutive parameters of poplar

\begin{tabular}{llllllllll}
\hline & $E_{\mathrm{R}}(\mathrm{MPa})$ & $E_{\mathrm{L}}(\mathrm{MPa})$ & $E_{\mathrm{T}}(\mathrm{MPa})$ & $\mu_{\mathrm{RL}}$ & $\mu_{\mathrm{LT}}$ & $\mu_{\mathrm{RT}}$ & $G_{\mathrm{RL}}(\mathrm{MPa})$ & $\boldsymbol{G}_{\mathrm{LT}}(\mathrm{MPa})$ & $\boldsymbol{G}_{\mathrm{RT}}(\mathrm{MPa})$ \\
\hline Value & 910 & 8431 & 910 & 0.2 & 0.47 & 0.43 & 915 & 732 & 219.6 \\
\hline
\end{tabular}




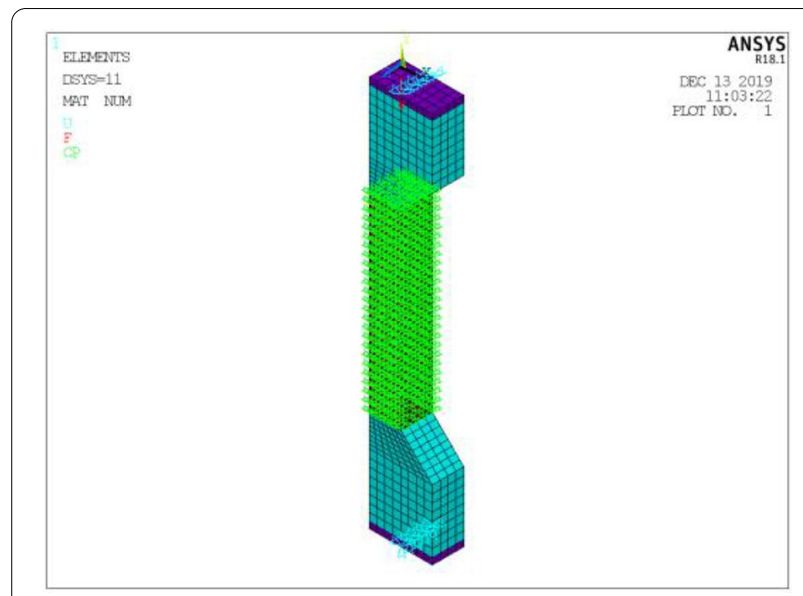

Fig.15 FEA model of column

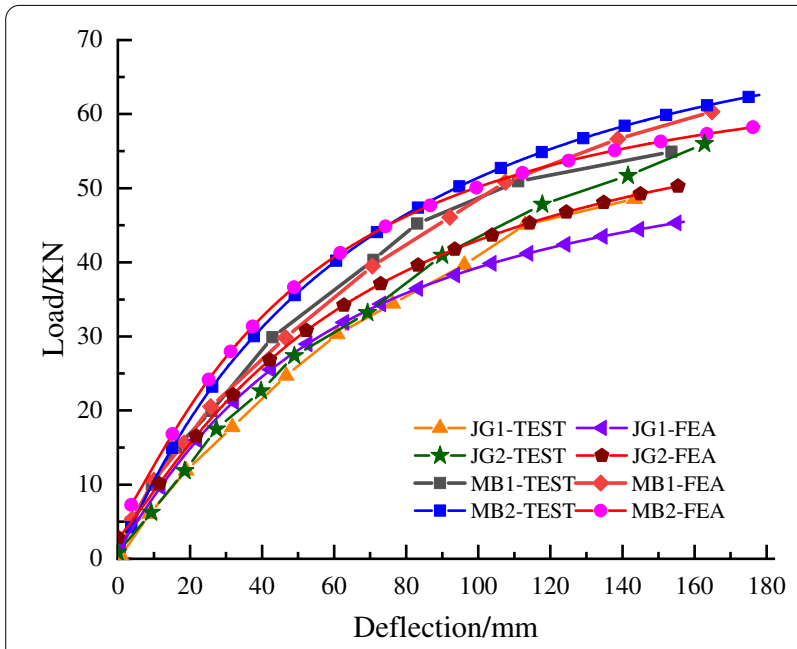

Fig.16 Curves of load-deflection of reinforced columns

specimen is damaged at this time. Similarly, for specimens MB1-100-1200 and MB2-100-1200, the wooden columns are in the elastic stage when the load is $0-36$ $\mathrm{kN}$, and the displacement of the specimen increases uniformly with the load; both specimens enter the plastic stage when the load exceeds $36 \mathrm{kN}$, the curve has an inflection point, the slope of the curve decreases, and the displacement rapidly increases until the limit load is $56 \mathrm{kN}$. Thus, the specimen is damaged at this time. The analysis result of the finite element model for the test piece is larger than the test result due to the following factors. (1) Wood is porous capillary colloid and its variability of material property is inherently relatively large $[56,57]$. By contrast, poplar is completely in an ideal state in modeling without the influence of some initial defects, such as knots. In addition, the compaction stage of the tubular cell fibers at the initial loading was not considered in the finite element analysis. (2) Environmental interference factors during the test, such as temperature and humidity, will also have a certain impact on the test. (3) Dimensional error of specimen. Something included in human error also might be due to movement of the loading stamp, eccentricity of the test machine, initial axial loading, etc.

Long columns from poplar with BFRP reinforcements are subjected to eccentric compressive load based on the long column bearing capacity formula. The "Wood Structure Test Method Standard" (GB50005-2017) indicates that the eccentric compressive bearing capacity should be calculated as follows [58]:

$$
\begin{aligned}
& \frac{N}{\varphi \varphi_{m} A_{0}} \leq f_{B c}, \\
& \varphi_{m}=(1-k)^{3}, \\
& k=\frac{N e_{0}}{W f_{m}\left(1+\sqrt{\frac{N}{A_{0} f_{B c}}}\right)},
\end{aligned}
$$

where $N$ is the design value of eccentric compression bearing capacity of long column $(\mathrm{N}) ; \varphi$ is the stability factor of the axial compression of the long column; $\phi_{m}$ is the reduction coefficient of long column combined with axial force and initial bending moment; $A_{0}$ is the calculated area of the long wooden column $\left(\mathrm{mm}^{2}\right) ; e_{0}$ is the initial eccentricity $(\mathrm{mm}) ; f_{B C}$ is the straight grain compressive strength $\left(\mathrm{N} / \mathrm{mm}^{2}\right) ; f_{m}$ is the flexural strength $\left(\mathrm{N} / \mathrm{mm}^{2}\right)$; and $W$ is the cross-section resistance moment of a long column $\left(\mathrm{mm}^{3}\right)$.

Based on the test data and the results of the finite element simulation, the bearing capacity of the long column under eccentric is calculated in accordance with Formulas (5)-(7). The calculation results are shown in Table 8. The comparison of the calculation result with the test value and the finite element simulation value revealed that both values are relatively close, the error from the test value is maintained at approximately $5 \%$, and the error from the finite element simulation value is approximately $1 \%$. These findings indicate that the calculation formula has certain feasibility. Compared with unreinforced columns, the bearing capacity of BFRP-reinforced wooden columns demonstrated an increase of $9.1 \%-25.8 \%$.

\section{Conclusion}

Poplar is a major feature in Xinjiang and has considerable importance in the application and development of wood structures in Xinjiang, China. The mechanical 
Table 8 Comparison of test and theoretical and FEA results about ultimate bearing capacity

\begin{tabular}{llllll}
\hline Column & $\boldsymbol{f}_{\mathrm{u}}$-TEST $(\mathrm{kN})$ & $\boldsymbol{P}_{\mathbf{u}}$-FEA $(\mathbf{k N})$ & Theoretical value $\boldsymbol{P}_{\mathbf{t}}(\mathrm{kN})$ & $\begin{array}{l}\text { Increment of } \boldsymbol{f}_{\mathrm{u}} \text { and } \boldsymbol{P}_{\mathbf{t}} \\
(\%)\end{array}$ & $\begin{array}{l}\text { Increment } \\
\text { of } P_{\mathbf{u}} \text { and } P_{\mathbf{t}} \\
(\%)\end{array}$ \\
\hline DBZ & & & & 5.0 & 1.4 \\
JB1 & 46 & 49 & 48.32 & 5.5 & 1.4 \\
JB2 & 50 & 52 & 52.73 & 3.1 & 0.5 \\
MB1 & 55 & 57 & 56.72 & 2.9 & 1.2 \\
MB2 & 57 & 56 & 55.36 & 1.3 & 1.3 \\
\hline
\end{tabular}

$P_{\mathrm{u}}$ is ultimate load of FEA; $f_{\mathrm{u}}$ is ultimate load of test

properties of long columns were studied in this paper based on a test. The ultimate load, deflection, and strain of reinforced columns under different eccentricities were also analyzed by the finite element method. The following conclusions were drawn.

The failure form of the wooden columns indicates that the specimens were prone to lateral deflection under vertical load. Deformation was dominated by typical longitudinal bending failure. Columns with BFRP fiber cloth spaced apart and wooden columns covered with BFRP fiber were susceptible to damage in the unreinforced and defective sections (such as wood knots), respectively.

Long wooden columns from poplar in Xinjiang were typical of longitudinal bending failure under stress. The failure of the wooden pillars was mostly the buckling of wood fibers along the grain direction of the wood in the compression zone. This phenomenon produced fiber failure in the tension zone. Compared with the unreinforced rectangular long column from poplar, the ultimate bearing capacity of the wooden column with axial compression was remarkably increased when the wooden column was reinforced with BFRP strips. The BFRP strips with one layer spaced apart, two layers spaced apart, one layer fully filled, and two layers fully reinforced wooden columns demonstrated increased bearing capacities of $3.13 \%, 30.00 \%, 40.63 \%$, and $65.00 \%$, respectively. The longitudinal strain increased by $7.54 \%, 19.65 \%, 22.06 \%$, and $30.69 \%$, and the lateral strain decreased by $26.53 \%$, $29.80 \%, 41.30 \%$, and $66.64 \%$, respectively.

For the wooden column subjected to eccentric compression, the ultimate bearing capacity of the wooden column was significantly improved compared with unreinforced wooden pillars when the wooden column was reinforced with BFRP strips. The BFRP strips with one layer apart, two layers apart, one layer full, and two layers fully reinforced wooden columns demonstrated increased bearing capacities of $8.70 \%, 19.56 \%, 23.91 \%$, and $30.43 \%$, respectively. The increase in the longitudinal strain of the wooden column was $25.41 \%, 35.20 \%$, $39.52 \%$, and $41.85 \%$, and the increase in transverse strain was $130.77 \%, 166.77 \%, 192.57 \%$, and $230.86 \%$, respectively. The longitudinal deformation increased by $12.61 \%, 18.54 \%, 27.17 \%$, and $40.51 \%$, and the lateral deformation increased by $214.76 \%, 243.15 \%, 260.98 \%$, and $264.58 \%$, respectively. The bearing capacity of spaced and fully affixed wood pillars with BFRP, respectively, increased by $14.13 \%$ and $27.17 \%$ considering the unreinforced wood columns. This finding indicates that the longitudinal bonding of BFRP strips can effectively improve the bending capacity of the wooden columns.

\section{Abbreviations}

BFRP: Basalt fiber-reinforced polymer; FRP: Fiber-reinforced polymer; CFRP: Carbon fiber-reinforced polymer; GFRP: Glass fiber-reinforced polymer; AFRP: Aramid fiber-reinforced polymer; FEA: Finite element analysis; LVDT: Linear variable differential transducer; DOF: Degree of freedom.

\section{Acknowledgements}

This study was conducted with the support of National Natural Science Regional Fund (51768069) \& Xinjiang Uygur Autonomous Region (2019D01C048) and Special Funds (CHD300102219525) for Fundamental Scientific Research Business Expenses of Central Universities.

\section{Authors' contributions}

QL planned and supervised the research. LZ analyzed the experimental data and wrote the manuscript. SQM and XH draw the all figures. All the authors read and approved the final manuscript.

\section{Funding}

This project is funded by Natural Science Grant of Xinjiang Uygur Autonomous Region and Fundamental Scientific Research Business Expenses of Central Universities.

Availability of data and materials

All data generated or analyzed during this study are included in this published article.

Competing interests

The authors declare that they have no competing interests.

Received: 14 July 2020 Accepted: 8 December 2020

Published online: 06 January 2021

References

1. Yang ZJ (2005) Timber structure: green structure of energy-conserving building. J Housing Mater Appl 33:50-52 
2. Liang SC (2005) History of Chinese architecture. Baihua Literature and Art Publishing House, China

3. Liang SC (2006) Examples of Qing-style construction. Tsinghua University Press, China

4. Zhao HT (2012) Chinese ancient building structure and its earthquake resistance. Science Press, China

5. Hao CR (2004) Looking at the prospects of chinese wood structure building from the development of Chinese and western wood structure buildings. Dissertation, Tsinghua University.

6. Li XM (2009) Research on mechanical property simulation of timber with finite element method and optimization of timber. Dissertation, Inner Mongolia Agricultural University.

7. Zhou Q, Yan WM, Li ZB (2009) Study on strengthening methods of timber structures of ancient buildings. J Earthq Resist Eng Retrofit 1:87-93. https ://doi.org/10.16226/j.issn.1002-8412.2009.01.014

8. Ou YLJ, Ding B, Lu ZD (2010) BFRP and its application review in structural strengthening. J Fiber Reinforced Plastics/Composites (in Chinese) 3:84-88

9. Xu WY (1988) Poplar. Heilongjiang people's publishing house, China

10. Zeng DP (2002) Review of current situation of research and control on poplar diseases in China. China forest Pests J 1:20-26

11. Lu J (2001) Studies on adaptability of populus bolleana and other poplar trees in northwest shanxi province. J For Res J 12:31-34. https://doi. org/10.1007/BF02856796

12. Shu QL, Chen CY, Zhang H (2005) Investigation of the species, occurrence character and control measures of poplar diseases in Anhui Province. J Anhui Agric Sci 7:1193-1195

13. Yuan C, Yu MJ (2017) Research on the method of strengthening wooden structures in ancient buildings. Urban Construct Theory Res 11:16-19. https://doi.org/10.19569/j.cnki.cn119313/tu.201703034

14. Xiong HB, Liu YY, Yao Y (2016) Experimental study of reinforcement methods and lateral resistance of glued-laminated timber post and beam structures. J Tongji Univ 44:695-702. https://doi.org/10.11908 /j.issn.0253-374x.2016.05.006

15. Zhou Q, Yan WM, Guan HZ (2013) An experimental study on aseismic behaviors of chinese ancient structure strengthened by different methods. J China Cult Herit Sci Res 2:60-66

16. Lantos $G$ (1970) The flexural behavior of steelreinforced laminated timber beams. J Wood Sci 2(3):136-143

17. Bulleit WM, Sandberg LB, Woods GJ (1989) Steel-reinforced glued laminated timber. J Struct Eng 115:433-444. https://doi.org/10.1061/ (ASCE)0733-9445(1989)115:2(433)

18. Bulleit WM (1986) Reliability model for wood structural systems. J Struct Eng 112:1125-1132. https://doi.org/10.1061/ (ASCE)0733-9445(1986)112:5(1125)

19. Liu YX, Zhao GJ (2012) Wood Science. China Forestry Publishing House, Beijing

20. Johns KC, Lacroix S (2000) Composite reinforcement of timber in bending. Can J Civ Eng 27:899-906. https://doi.org/10.1139/100-017

21. Khelifa M, Celzard A, Oudjene M, Ruelle J (2016) Experimental and numerical analysis of cfrp-strengthened finger-jointed timber beams. Int J Adhes Adhes 9:283-297. https://doi.org/10.1016/j.ijadhadh.2016.04.007

22. Khelifa M, Lahouar MA, Celzard A (2015) Flexural strengthening of fingerjointed spruce timber beams with cfrp. J Adhes Technol 29:2104-2116. https://doi.org/10.1080/01694243.2015.1057395

23. Sotayo A, Green S, Turvey G (2016) Experimental and finite element (fe) modelling of timber fencing for benchmarking novel composite fencing. Compos Struct 158:44-55. https://doi.org/10.1016/j.compstruct 2016.07.082

24. Li XM, Xu QF, Zhu L (2009) Experimental research on CFRP-strengthened old timber columns. J Earthq Resist Eng Retrofit 31:55-59. https://doi. org/10.3969/j.issn.1002-8412.2009.04.011

25. Ma JX, Hu P, Jiang XM (2005) Experimental research on axial compressive behaviors for timber column strengthened with CFRP. J Ind Construct 35:40-44. https://doi.org/10.3321/j.issn:1000-8993.2005.08.009

26. Zhou ZH, Liu WQ (2006) Experimental study on timber columns strengthened by CFRP subjected to axial compression. J Earthq Resist Eng Retrofit 3:47-51. https://doi.org/10.3969/j.issn. 1002-8412.2006.03.009

27. Zhou Q (2009) Study on characters of axial pressure of timber column reinforced by CFRP. J Low Temp Architect Technol 135:51-53. https://doi. org/10.3969/j.issn.1001-6864.2009.09.023
28. Shao JS, Liu WQ, Jiang $T$ (2008) Stress-strain model for FRP-strengthened wood column under axial compression. J Eng Mech 25:183-187. https:// doi.org/10.1016/S1872-5791(08)60058-5

29. Ouyang Y, Huang YH, Qian ZZ (2002) Analysis of the ultimate strength of concrete square-columns strengthened with GFRP sheet under axial compression. J Ind Construct 32:54-56. https://doi.org/10.3321/j. issn:1000-8993.2002.06.018

30. Zhou ZH (2005) Experimental research on the axial compression of wooden columns reinforced with CFRP. In: Liu Weiqing (ed) In: Proceedings of the young mechanics forum of Jiangsu Mechanical Society, Jiangsu, 2005 (in Chinese).

31. Zhang TY (2005) Experimental research about old timber column wrapped by CFRP sheets. J Fujian Architect Construct 2:55-57

32. Xie QF, Zhao HT, Ge HP (2007) Experimental study on axial compressive behaviors for timber column strengthened with CFRP sheets. J Build Struct 37:96-99

33. Omar C, Mohsen S (2000) Performance of fiber reinforced polymer wrapped reinforced concrete column under combined axial flexural loading. J ACl Struct J 97:659-668

34. Xian QL, Yi WJ, Ding HT (2004) Experiment and research of reinforced concrete column externally bonded with CFRP sheets under eccentric load. J Ind Construct 34:78-81. https://doi.org/10.3321/j. issn:1000-8993.2004.11.021

35. Chen ZP, Zhong MP, Chen YL (2014) Mechanical behavior and computed bearing capacity of steel reinforced recycled-aggregate-concrete columns under eccentric loading. J Eng Mech 31:160-170. https://doi. org/10.6052/j.issn.1000-4750.2012.11.0851

36. Xu QF, Zhu L (2007) An experimental study on partially-damaged wood columns repaired and strengthened with CFRP. J China Civil Eng J 8:41-46. https://doi.org/10.3321/j.issn:1000-131x.2007.08.007

37. Xu QF, Zhu L, Gong CC (2007) Experimental research on short timber columns strengthened with CFRP. J Construct Technol 5:17-19. https:// doi.org/10.3969/j.issn.1002-8498.2007.05.004

38. Zhu L, Xu QF, Dai GH (2009) Experimental research on short cracked timber columns strengthened with CFRP. J Build Struct 39:101-103

39. Ou YY, Gong Y (2012) Experimental research on cracked timber columns strengthened with CFRP under eccentric load. J Shanghai Univ 18:209-213. https://doi.org/10.3969/j.issn.1007-2861.2012.02.019

40. Ouyang $Y$, Wang $W$, Gong $Y$ (2012) The ultimate load-bearing capacity of timber columns strengthened with CFRP under eccentric load. J Ind Construct 42:146-149. https://doi.org/10.13204/j.gyjz201210030

41. GB/T 1931-2009 (2009) Methods for determination of wood moisture content. People's Publishing House, Beijing

42. GB/T1928-2009 (2009) General Test Methods for Wood Physics and Mechanics. China Standard Press, Beijing

43. GB/T 1938-2009 (2009) Method of testing in tensile strength parallel to grain of wood. China National Standard, Beijing

44. GB/T 1935-2009 (2009) Method of testing in compressive strength parallel to grain of wood. China National Standard, Beijing

45. Yue QR, Yang YX (2003) Introduction of "Technical Specification for Reinforcement and Repair of Concrete Structures with Carbon Fiber Sheets." J Build Struct 6:69-72

46. GB 50608-2010 (2010) Technical specification for construction engineering application of fiber reinforced composite materials. China National Standard, Beijing

47. GB/T 50329-2012 (2012) Standard for test methods of timber structures. China National Standard, Beijing

48. ANSYS (2009) ANSYS online manual. ANSYS Inc., Canonsburg, PA

49. Jeong GY, Park MJ (2016) Evaluate orthotropic properties of wood using digital image correlation. J Construct Build Mater 113:864-869. https:// doi.org/10.1016/j.conbuildmat.2016.03.129

50. Wang XM, Li YQ, Xu HW (2011) ANSYS structural analysis unit and application. People's Communications Press, China

51. Mikami H, Kishi N, Kurihashi Y (2000) Flexural bonding property of frp sheet adhered to rc beams. J labse Congress Report 16:11-19. https://doi. org/10.2749/222137900796314158

52. Guan BH (2013) Analysis of the interface bonding mechanism of AFRPstrengthened reinforced concrete beams. Doctoral dissertation, South China University of Technology. 
53. Chen L, Wei WD, Cui HT (2013) Generalization of Hill's yield criterion to tension-compression asymmetry materials. Sci China Technol Sci 1:89-97. https://doi.org/10.1007/s11431-012-5037-9

54. Abbas V, Rijun S, Keith C (2018) Bond strength model for externally bonded FRP-to-timber interface. J Composite Struct 200:328-339. https ://doi.org/10.1016/j.compstruct.2018.05.152

55. Juvandes LFP, Barbosa RMT (2012) Bond Analysis of Timber Structures Strengthened with FRP Systems. J Strain 48:124-135. https://doi.org/10.1 111/j.1475-1305.2011.00804.x

56. Shi GR (1988) Wood viscoelasticity and its creep model. J Beijing For Univ 10:88-94
57. Zhang QK (2011). Finite element modeling and force-thermal performance calculation of wood microstructure. Dissertation, Lanzhou University of Technology (in Chinese).

58. Ministry of Construction of the People's Republic of China (2017) Code for design of wooden structures. China Building Industry Press, China (in Chinese)

\section{Publisher's Note}

Springer Nature remains neutral with regard to jurisdictional claims in published maps and institutional affiliations.

\section{Submit your manuscript to a SpringerOpen ${ }^{\circ}$ journal and benefit from:}

- Convenient online submission

- Rigorous peer review

- Open access: articles freely available online

- High visibility within the field

- Retaining the copyright to your article

Submit your next manuscript at $\boldsymbol{\nabla}$ springeropen.com 